\title{
Erratum
}

Arch. Pharm. Res. Vol.21, No.1, pp. 62-66, 1998

\section{Screening and Isolation of Antibiotic Resistance Inhibitors from Herb Materials-Resistance Inhibition of Volatile Components of Korean Aromatic Herbs}

Chung Kyu Lee, Hyekyung Kim, Kyung Ho Moon and Kuk Hyun Shin*

College of Pharmacy, Kyungsung University, Pusan 608-736 and *Natural Products Research Institute, Seoul National University, Seoul 110-460, Korea

The unit of concentration in Figures 1,2 and 3 should be $\mu \mathrm{g} / \mathrm{ml}$, not $\mathrm{mg} / \mathrm{ml}$. 